\title{
Evaluación del DoceNTE en La UNIIERSIDAD DE ChILE: La MIRAda desDe los EstUdiaNTes.
}

Teacher 's Evaluation in the University of Chile: The Students' Point of View

\author{
Adrián Baeza Araya \\ Especialista en Literatura Chilena e Hispanoamericana \\ Digonal Paraguay 265, Santiago \\ Universidad de Chile \\ abaeza@uchile.cl
}

\begin{abstract}
Resumen: El texto propone un modelo de Evaluación del Docente con propósitos de desarrollo de la profesionalidad mediante un acercamiento evaluativo que prioniza la cultura docente de las unidades académicas en que se inserta el docente, reconociendo la dimensión colectiva-institucional de la docencia como fuente de legitimidad, desarrollo y orientación de la docencia. Se perfila un objeto evaluativo para el modelo, centrado en el conocimiento, y se abordan las dimensiones, categorías y criterios de ese objeto que permiten una mirada comprehensiva y compleja del desempeño docente. Pretende actuar como un recorte de la mirada de los estudiantes que otorgue pertinencia a la información que deben proveer acerca de cómo el docente vincula tres procesos: conocimiento, enseñanza y aprendizaje.
\end{abstract}

Palabras claves: Evaluación docente, modelo evaluativo, cultura docente, evaluación docencia.

Abstract: The text proposes a model of Teacher Evaluation intended for professional development, by giving a central role to the pedagogic culture of the academic unit to which the teacher belongs to aiming a recognition of institutionalcollective dimension of teaching as a main source for development, legitimacy, and orientation of teaching. An evaluative object for the model becomes outlined - in terms of knowledge - and its evaluative dimensions, categories and criteria are taken into account as they contribute to a broader and more complex understanding of teaching. This object is meant to be a focus of student's point of view regarding pertinence for the information students provide on how the teacher relates three processes: teaching, knowledge and learning.

Key words: Teacher's evaluation - Evaluative model - teacher's culture - teaching evaluation.

\section{INTRODUCCIÓN}

La Universidad de Chile es una universidad compleja no sólo en virtud de la multiplicidad de funciones que en su interior se desarrollan, sino en relación con su constitución interna, en términos de subculturas docentes, disciplinas, prácticas y personas. Dar cuenta de esta heterogeneidad haciendo justicia de ella; es decir, convirtiendo la diversidad en una fortaleza, pero a la vez trazando la ruta para que los esfuerzos locales converjan con armo- 
nía, desde la óptica global de la institución, plasmando así sus objetivos estratégicos, orientados al mejoramiento continuo de la calidad de la docencia, no resulta una tarea fácil al momento de pensar la evaluación del docente; en particular, debido a un problema conceptual al interior del campo educativo.

En particular si recordamos a Comenio, atravesando distintas epistemes, que van desde la teología, en los albores de la modernidad, a la biología, la psicología durante todo el siglo $\mathrm{XX}$, y en sus últimas décadas a la teoría crítica y los estudios culturales, ha persistido una conceptualización, que podríamos denominar metafísica, del hecho pedagógico: la conceptualización de éste como un compuesto de individualidades (el docente - el alumno), y en particular, en lo relativo a los docentes. Es así como se parte suponiendo una relación dual docente-alumno 0, en el mejor de los casos, docente-estudiantes. Queda inexplorada, de esta suerte, la dimensión social del hecho pedagógico, pues se olvida que el proceso de formación de los sujetos lo realiza, en primera instancia, una institución. La racionalidad pedagógica del sujeto es vista, entonces, como rigurosamente individual, quedando fuera, por tanto, determinantes centrales a la hora de pensar la relación que en el aula éste establece con sus interlocutores. Es más, en opinión de Natriello, citado por Millman y Darling - Hammond (1997), "la enseñanza es una ocupación en la cual los profesores individuales actúan solo y lejos de la mirada de otros colega adultos. Lo que es más, la naturaleza de la docencia deja a los profesores con una sensación de inseguridad acerca de su propio rendimiento y de los efectos que el mismo tiene sobre los estudiantes, (p55).

Tal vez sea la influencia determinante de dicho espacio, la sala de clases, en el imaginario pedagógico, lo que ha jugado en ese recorte del constructo. "El espacio dominante del ejercicio profesional es el aula, un espacio aislado" afirma Gimeno Sacristán (1997; p142), apuntando en la misma dirección; lo cierto es que nos hemos habituado a pensar en la figura de un docente solitario, en un aula solitaria, al que es preciso auxiliar desde todas las ciencias posibles para prestarle guías en su labor. En opinión de Schulman, (2001) la psicología tiene asimismo una cuota de participación en esta imaginería. "Los estudios sobre enseñanza tienen lugar en aulas convencionales. En cambio, el aprendizaje y el desarrollo son estudiados comúnmente mediante la observación de individuos. Por ende, los estudios sobre la enseñanza dan cuenta de la manera en que los profesores hacen frente al carácter ineludible de los recintos escolares como lugares donde grupos de estudiantes trabajan y aprenden en conjunto. En contraste, los estudios sobre el aprendizaje y el desarrollo generan principios de pensamiento o comportamiento individuales que a menudo deben hacerse extensivos con cautela a los grupos" (p179). Un divorcio viene a darse entre teorización y práctica, no sólo desde la relación de hegemonía que la psicología ha tenido con el campo educativo, sino al interior mismo del campo, interiorizando el mismo 
esquema de comprensión. "Los métodos de formación se basan en una perspectiva individualista de la práctica profesional. Pero la práctica, en cambio, tiene un carácter socializado" (Gimeno, 1997; p143).

\section{EL DOCENTE Y LA DOCENCIA}

El camino de la evaluación de esta figura solitaria ha estado compuesto por el paisaje de una evaluación centrada en el individuo más que en el rol profesional, haciendo esencial la labor docente en un modelo vocacional, mezclado con una orientación básicamente destinada al control del sujeto, control administrativo en búsqueda del logro de la eficiencia mucho más que de la eficacia, y menos aun de la evaluación en pro de la mejora del quehacer docente, la que no deja de tropezar a cada momento con los obstáculos puestos al ojo evaluador por la olvidada dimensión colectiva de la labor docente. Félix Angulo Rasco (1996) sostiene que "tanto control como mejora son, en realidad, conceptos polisémicos y cargados de significaciones no todas ellas aceptables, aunque su percepción social se encuentre fuertemente denotada. Si invocar el control lleva consigo el rechazo inmediato, la invocación de mejora, parece arrastrar algunas adhesiones. Se olvida que el control, entendido como control público debería ser una parte sustancial del funcionamiento de las instituciones públicas; y se olvida además, que dicho control no es antitético con la idea de mejora de la calidad que tendría que venir asociada a cualquier proceso de evaluación" (p169). Si bien concordamos con estas precisiones de Rasco, no es menos cierto que debe existir, en lo que a evaluación del docente se refiere, una clara atribución de los rangos de mirada de los agentes informantes que aportan a la evaluación sea para el control, sea para la mejora. En este sentido estimamos necesario delimitar atribuciones, demarcando el espacio de uno y otro propósito en función de quién informa sobre qué. A esto nos referiremos luego.

Un profundo error de interpretación se produce a partir de este olvido, llevando a conceptualizar brusca y toscamente la relación entre el espacio del aula y el contexto extrainstitucional. Atribuimos al docente individual la responsabilidad de ser el puente entre la realidad protegida del aula y el espacio demandante del mundo laboral y de la vida en que deben insertarse los egresados de la institución. Pero dejamos de atribuirle a ella, a la institución, esa relación de mediación con el entorno, y más aún, la despojamos del rol fundamental que cumple en el proceso de formación del estudiante al interior mismo del aula. En este sentido entenderemos docencia como la labor institucional de formación de sujetos a partir del desempeño de los docentes individuales que plasman en sus prácticas una convergencia de ideales, prácticas, creencias y conocimientos tanto explícita como implícitamente declarados y cohesivos. 
Esa función mediadora y formativa de la institución viene dada por su calidad de agente colectivo en ambos procesos (de vinculación interiorexterior y de formación). Al interior de esos procesos el docente individual es sólo un componente cuya remembranza nostálgica en la lejanía de la vida adulta, depende de factores como el carisma, la epifanía o el trauma. De no incorporar la dimensión colectiva e institucional de la docencia en los procesos de desarrollo y evaluación del docente, lo que se hace es entender la formación de un sujeto como la mera sumatoria de acciones individuales. En este marco, caemos en una paradoja: exigimos cada día más al docente la contextualización de su práctica de acuerdo a las características de sus estudiantes (conocimientos previos, cultura, edad, etc.) y la mayor vinculación de su didáctica con las presiones y posibilidades del entorno, a la vez que descontextualizamos el esfuerzo de ese mismo docente, desinstitucionalizando su quehacer y dejándole solo ante esos dos frentes. No es extraño, entonces, el fenómeno que muestran algunas de las encuestas de evaluación del docente que circulan en una Universidad como la nuestra: se atribuyen a la responsabilidad del docente múltiples factores cuya jurisdicción corresponde al nivel institucional. La falta de claridad en la función mediadora de ella deviene en deslindes borrosos y hasta perjudiciales para la estimación del desempeño docente.

La institucionalidad del proceso de formación de los estudiantes es un fenómeno al que no nos habituamos aún. En el mejor de los casos, ella ha venido a situarse como un imperativo: es preciso ponernos de acuerdo, hacer esfuerzos de articulación, de sinergia.. Ese imperativo no deja de ser sentido como un agregado, como algo externo, cuya condición de posibilidad es la realización de un esfuerzo institucional. A este imperativo se le ha denominado el paradigma de la colegialidad. Es preciso diferenciar lo que para nosotros es un reconocimiento, esto es que toda docencia tiene, de suyo, una dimensión colectiva en el hacer singular, de lo que es un esfuer-

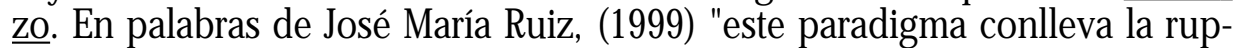
tura del individualismo, la planificación conjunta, la reflexión compartida, la coordinación intensa, la acción colegiada. El centro aparece como la unidad funcional de planificación, trabajo, innovación y evaluación". Para este autor, "Esta nueva situación exige un contexto que permita llevarlo a cabo"(pág 7). Abandonar de pronto la aceptación de la soledad docente para adherir al polo de la colegialidad no hace sino refrendar la existencia de esa soledad como punto inicial de un continuum en cuyo extremo opuesto se sitúa lo ideal. Para nosotros, en cambio, el supuesto es que la docencia ha sido y sigue siendo, de suyo, una actividad colectiva, lo cual es más notorio en el caso de la docencia universitaria.

G.H. Mead primero, y luego Vygotski insistieron en la dualidad de la constitución del sujeto mediante la proposición de que el proceso que los informa es a la vez individual y social. Vygotski (1988) afirma que toda función de la estructura cognitiva de un sujeto ha sido previamente un rasgo 
de la colectividad dentro de la cual ese sujeto se inserta. Dicha relación sujeto-colectividad se establece como un puente que explica la relación de continuidad y diferencia que cada individuo instituye al interior de sus prácticas en función de su cultura. La formación sociogenética del individuo no puede dejar de pensarse al interior de instituciones sociales en que se organizan los grupos humanos. Para el caso de la docencia universitaria, todos los miembros del cuerpo docente han sido inmersos en diversas prácticas pedagógicas a lo largo de su sociogénesis escolar: han sido largamente formados por el sistema educativo en sus varios niveles, pero asimismo al ingresar en una unidad académica en particular, desde su calidad de estudiantes, y luego ayudantes, hasta los grados más altos de la jerarquía académica, han ido apropiándose del discurso y las prácticas legítimas dentro de esa misma unidad, sus valoraciones, creencias, requerimientos, disciplina, frames, etc. Se apropian, poco a poco, en términos de Bourdieu, de su habitus. Para Bourdieu, (1997) "los habitus son principios generadores de prácticas distintas y distintivas (...) pero también son esquemas clasificatorios, principios de clasificación, principios de visión y de división, aficiones, diferentes. Establecen diferencias entre lo que es bueno y malo, entre lo que está bien y lo que está mal, entre lo que es distinguido y lo que es vulgar, etc" (p29). El concepto de habitus así descrito nos ayuda a comprender la génesis social-individual de las decisiones y actuaciones docentes de un individuo.

Prescindir de la dimensión social nos lleva a una imaginería racionalista en la cual la práctica docente se explica en virtud de su exclusiva voluntad racional, sin mediatizaciones de ningún tipo que den cuenta de la naturalidad, o legitimidad, de su proceder en tales 0 cuales situaciones. Legitimidad alude, en este contexto, al carácter de "una institución, una acción o una costumbre que es dominante y no se conoce como tal, es decir, que se reconoce tácitamente" (Bourdieu, 1990, p133). Tal legitimidad proviene de la institucionalidad de la acción docente a la cual nos hemos referido. Bourdieu lo expone en términos discursivos al afirmar que "la situación legítima es algo en lo cual interviene a la vez la estructura del grupo y el espacio institucional dentro del que funciona este grupo", pues "para que funcione el discurso profesoral común, que se enuncia y recibe como algo natural, se requiere de una relación de autoridad-creencia, una relación entre emisor autorizado y un receptor dispuesto a recibir lo que aquél dice, a creer que merece la pena decirse. Es necesario que se produzca un receptor dispuesto a recibir, pero no es la situación pedagógica la que lo produce", (1990, p127), sino su institucionalidad o su dimensión de discurso vicario, pues el docente sólo enuncia su discurso o toma decisiones en virtud de su propia voluntad, sino en función de la autoridad que ha sido delegada en él. Así, lo colectivo es un marco de una naturalidad tal que nos hemos habituado a su transparencia en la cotidianeidad y a su casi inexistencia a nivel de la discusión teórica. 
Productos de la interacción cotidiana de los sujetos y sus prácticas tanto materiales como simbólicas, lo relevante del habitus docente de una unidad académica es que alberga modos de ver y entender el fenómeno pedagógico, sea desde una comprensión medianamente especializada o totalmente profana, desde los cuales enfrentar la cotidianidad del aula. Reconceptualizar la figura del docente, en particular del docente universitario, en el marco del colectivo académico del que forma parte, y de su subcultura, significa trabajar echando por tierra, necesariamente, el supuesto de sentido común según el cual los docentes universitarios carecen de conocimientos sobre educación y pedagogía, como si la práctica cotidiana que vienen realizando se desarrollase ex nihilo.

\section{EVALUACIÓN DOCENTE: ¿CUÁL ES EL PUNTO DE VALORACIÓN?}

El problema de "la falta de un modelo ideal de profesor universitario que sea aceptado por la comunidad educativa y que pueda constituir un punto de referencia para establecer un sistema de evaluación" (de Miguel, 1991), del que dan cuenta ciertos autores, no nos habla tanto de problemas propios de las comunidades académicas a quienes ese ideal se intenta imponer, como de una problemática epistemológica a nivel de la evaluación, problemática común por demás al estatuto contemporáneo del conocimiento, y que tiene que ver con las dificultades a la hora de enfrentar una realidad heterogénea, dinámica, a veces impredecible. Trabajar para el desarrollo del quehacer docente, entonces, desde la perspectiva del docente individual, no hace sino reiterar el error del perfeccionamiento descontextualizado, singular, y llevado a cabo lejos del aula en el tiempo y el espacio; es el olvido de la dimensión social que constituye la práctica del docente individual, el olvido de ese habitus pedagógico que nos obliga a hacer un giro radical, si pretendemos un proceso evaluativo que resulte relevante.

\section{LA BÚSQUEDA DE EQUILIBRIOS}

En el centro del proceso evaluativo, sin duda, no podemos dejar de situar al docente individual, en tanto que toda institución se compone de personas. Es el docente quien realiza la labor cotidiana de formación de los futuros cuadros profesionales y científicos de nuestro país.

No obstante, si nos situamos desde el paradigma positivista de la evaluación, obediente a la premisa epistemológica de mantener claramente diferenciados al objeto observado y al observador, otorgaremos un estatus pasivo a este sujeto, pues nuestro esfuerzo buscará homogeneizar al máximo la realidad con la cual se trabaja. Desde esa intencionalidad se sustenta la idea de que "la complejidad de factores implicados en la enseñanza universitaria impide el diseño de un modelo de profesor y por lo tanto la posibilidad de 
construir un sistema de evaluación que sea aceptado mayoritariamente" (de Miguel, 1991, p16). Villa Sánchez y Morales Vallejo, (1993) asimismo, señalan que "cualquier método de evaluación lleva consigo un modelo implícito 0 explícito de enseñanza. Esto significa que para evaluar al profesor es necesario un conocimiento del tipo de enseñanza que se pretende desarrollar, de modo que la evaluación se ajuste a este modelo y no pierda su sentido" (pág 23).

El evaluador concentra en sí todos los rasgos de agente del proceso: es él quien delimita el objeto, construye y operacionaliza la variable y selecciona los instrumentos. Contra esta condición subalterna del docente en el proceso evaluación, contra su condición objetual, intentamos el paso a una acción en que ese mismo docente adquiera una cuota de agenciamiento en el origen y desarrollo de la evaluación, pero en el marco de su integración a un colectivo que otorga sentido a su quehacer y del cual él es parte constitutiva. En este sentido, el modelo propuesto en estas páginas está cruzado por una voluntad de reconocimiento, y de gestión positiva, de la diversidad de subculturas docentes al interior de una Universidad compleja.

Ello nos lleva a dar la palabra a estos docentes en la construcción de una norma evaluativa con la cual cotejar el objeto evaluado; y por otra, a abandonar la intención de contar con un modelo ideal único de docente que pueda emplearse indistintamente en una y otras unidades, abandonando la idea de que "toda aproximación al tema de la evaluación del profesorado universitario debe partir precisamente de la elaboración de un modelo sobre cómo debe realizarse esa función en la práctica y someter a información pública dicho modelo con el fin de estimar el grado de consenso que existe sobre el mismo" (de Miguel 1991, pág 17). Más que un problema conceptual 0 técnico a resolver, la inexistencia de un modelo único de perfil o ideal docente debe considerarse, en la enseñanza universitaria, como una conditio sine qua non, toda vez que se reconozca el carácter situado que es preciso conceder a la relevancia del hecho pedagógico. Ese carácter situado es visible desde el reconocimiento de su inscripción en el habitus docente de una unidad particular. La construcción de estándares evaluativos extrínsecos al grupo al que se aplican se hace bajo la suposición de que ellos conducirán el desempeño de los sujetos a guisa de referentes. Una importante brecha se establece, sin embargo, entre esos referentes y los referentes cotidianos de la reflexión pedagógica de esos sujetos, deviniendo en externalidades frente a las cuales se debe cumplir, pero frente a las cuales no necesariamente surge el compromiso. Ante esto, hemos preferido realizar un trabajo detenido con cada unidad académica para determinar la norma evaluativa de cada una de ellas. Este proceso de acuerdos es capital, pues la comunidad docente no es sólo, no puede serlo, la sumatoria de las individualidades. El proceso de acuerdo fortalece, explicitando el soporte reflexivo de la unidad, la relación individuo-institucionalidad, a la vez que lo conduce. A este respecto hemos asumido al distinción evaluación del mérito y del valor del docen- 
te. Villa Sánchez y Morales Vallejo las distinguen en cuanto que el mérito 0 valía "se refiere a la excelencia profesional del profesor" (1993) en un sentido individual y omnicontextual, en la medida en que está referido al individuo en sí; mientras el valor del docente hace alusión a "la contribución que hace a la institución" (p39), en un sentido situado, contextualizado.

\section{CATEGORÍAS DE TRABAJO}

Los modos de hacer docencia que permean las culturas locales de las unidades académicas pueden entenderse como teorías implícitas. "Puesto que los practicantes de la educación deben poseer de antemano alguna comprensión de lo que hacen, así como un conjunto complejo, aunque tal vez no explícito, de creencias según las cuales sus prácticas adquieren sentido, es necesario que posean asimismo algún tipo de 'teoría' que les sirva para explicar u orientar su conducta" (Gimeno, 1997; p143).

Mediante tres categorías amplias, énfasis en contenidos, en objetivos y en procesos, pretendemos solucionar la tensión entre dar cuenta de conocimientos profanos y conocimientos especializados con que pudieran contar los diversos docentes evaluados al interior de la Universidad. Estas categorías permiten un paso graduado y coherente desde estadios de conocimiento iniciales e implícitos a otros más especializados y explícitos. Creemos que, necesariamente, si el docente ha de ser valorado en función de un perfil ideal, debe estar en condiciones de argumentar su proceder y comprender la información que se le provea en los términos de ese perfil.

A estas tres grandes categorías de comprensión de la docencia universitaria las hemos denominado "énfasis", puesto que los desempeños no son una cuestión de blanco o negro: un énfasis en contenidos, en objetivos y en procesos de aprendizaje, con el fin de acentuar la idea de que no consideramos la labor docente en términos de la adscripción a un modelo único de docencia. Si bien en el plano teórico la realidad se ordena, reduce y formaliza, el discurso y la reflexión docentes en la cotidianeidad son bastante más espurios. Olvidar ese carácter de mixtura intentando trazar rutas claras y distintas como ocurre en lo teórico se volvería, a poco, andar, en un pie forzado que reproduciría la posición subalterna del docente en el contexto de la evaluación positivista. Hemos preferido acercarnos a los referentes de la reflexión docente cotidiana, alejándonos de un lenguaje estrictamente pedagógico y acercándonos a una suerte de estadio intermedio. En el camino de una evaluación para el desarrollo docente, estas tres categonías permiten ese paso mediante la desagregación de cada una en subcategonías que permiten dar cuenta de formas más especializadas de desempeño docente.

Énfasis en Contenidos. Centrado ya en el valor de la reproducción epistemológica del conocimiento acumulado ya en sus estructuras de generación, con una didáctica de tipo transmisiva, para el primer caso, o bien, de 
tipo investigativo-academicista, para el segundo. La relación pedagógica es heterónoma, dada la disparidad de los sujetos en la posesión del conocimiento. El saber se encuentra mayormente desvinculado de sus aspectos prácticos y, naturalmente, del contexto.

Énfasis en Objetivos de Logro. Caracterizada por una racionalidad técnica preocupada por la productividad y la eficiencia. Su eje es el logro de estándares de desempeño. Promueve una didáctica asimismo heterónoma, con énfasis en el empeño de modificar las conductas de los sujetos. La relación entre conocimiento y práctica es operatoria, instrumental, de control y aplicación, con acento en una función técnica.

Énfasis en Procesos de Aprendizaje. Se coordinan aquí tres concepciones de la educación: la convergente y no convergente que Romeo agrupa como Perspectiva Holística, junto con la Perspectiva práctica o corriente crítica . La relación pedagógica tiende a ser paritaria, pues el conocimiento es un producto articulado donde participan sujetos en un proceso educativo de consenso de significados, con tolerancia a la diversidad. El centro del proceso educativo es el alumno. La relación del conocimiento disciplinario con la práctica es de apropiación y transformación; la meta es la formación integral del sujeto.

Estas categorías se relacionan en su génesis con las perspectivas del currículo que ella ha propuesto en relación con la educación superior. Para Romeo, (1998) una perspectiva "implica una configuración posible de preestablecer, sobre la base de criterios de interpretación que constituyen sistemas de significado específicos" a partir de lo cual entiende como perspectiva curricular la "red de significados que se establece a partir de los principios, la misión y las metas que se delimitan para precisar las diversas opciones que se reconocen en la selección y organización del conocimiento estimado como legítimo o legitimable" (p57). Desde esta definición semiótica de perspectiva se levantan cuatro categorías: perspectiva academicista, perspectiva práctica, perspectiva técnica y perspectiva holística. Nuestra propia categorización coincide en dos términos con esta. A las perspectivas academicista y técnica corresponden el énfasis en contenidos y el énfasis en objetivos. Sólo en el caso del énfasis en procesos nos ha parecido que era necesario considerar la orientación crítica, llamada práctica en el esquema de Romeo, pues comparte elementos importantes con las dos sub perspectivas que conforman la perspectiva holística, en particular la consideración a las condiciones sociohistóricas del sujeto particular con quien se establece la comunicación pedagógica, lo cual sitúa a esta perspectiva del otro lado del academicismo y los objetivos.

Por otro lado, el modelo de Porlán que introduce en Colombia Tamayo Valencia muestra tres categorías similares a las nuestras: currículo tradicional u obsesión por los contenidos, enfoque tecnológico u obsesión por los 
objetivos, y el enfoque espontaneísta u obsesión por los alumnos. Estas tres categorías están atravesadas por tres áreas de preocupación: pautas de acción, creencias y dilemas. Si bien no podemos extendernos en el comentario de este modelo, nos contentaremos con apuntar que no nos satisface la caracterización que de las categorías se realiza en términos de las adscripciones implícitas a una y la crítica velada de las otras. Es visible, por ejemplo, en la descripción del currículo tradicional (palabra que de suyo permea una carga de negatividad), al sostener que la determinación de qué enseñar está signada por la "elaboración de un temario de contenidos basado exclusivamente en los productos de las disciplinas", o en la referencia a que las forma de enseñar se remiten a "explicación verbal de cada tema, siguiendo directa o indirectamente un libro de texto" (Tamayo, 1999; p42).

En contraste, la conceptualización que hace Romeo nos parece más justa en la medida en que resulta menos gratuita. Señala esta autora en relación con las formas de enseñanza que ellas consisten en "una exposición de ideas y reproducción de ellas, desde una óptica; y reconocimiento de ideas directrices de configuración de estructura disciplinaria, desde otra" (1998; p59). Junto al hecho de una descripción más equilibrada y menos apasionada de la perspectiva, descripción que no induce a demonizaciones prematuras, se encuentra el hecho significativo de reconocer un matiz en la perspectiva, constituido por las sub perspectivas comprensiva y enciclopédica. Ahora bien, requeríamos usar categorías que estuvieran relacionadas con el lenguaje de los docentes pero que no estuvieran necesariamente cargadas de connotaciones previas, como ocurre con los conceptos de "obsesión" en Tamayo y de "academicismo" en Romeo. Lo fundamental, sin embargo, fue que nos dimos cuenta de que emplear un número elevado de categorías nos obligaba a adoptar el supuesto de que era posible distinguir clara y distintamente estas categorías en la descripción y el discurso de las comunidades académicas de la Universidad, lo que implicaba una cuota de explicitación del saber pedagógico de parte de los profesores. Optamos, así, por emplear solo tres grandes términos que pudieran ar cuenta de una gran heterogeneidad de prácticas a la vez que permitieran esa heterogeneidad y propiciaran su gestión positiva. Ello nos convenció de la necesidad de no trazar las categonías desde valoraciones previas, pues estimamos central la idea de que una pedagogía relevante no puede dejar de ser situada.

Los tres énfasis o perspectivas de la docencia suponen la posibilidad de mezclarse en diversos niveles del fenómeno pedagógico, evitando la idea de convertirse en estancos que deban seguirse implacablemente. El núcleo que articula a todos ellos es el objeto que en cada uno y entre todos ellos es posible conceptuar como el punto central de la docencia universitaria que hasta ahora ha permanecido obnubilado por la orientación al control que tienen las prácticas evaluativas. Nos referimos al objeto constituido por la relación establecida entre tres factores que, de simples, suelen olvidarse: los procesos de enseñanza, de aprendizaje y de conocimiento. 
César Coll citado por Marchesi (2000) ha propuesto un triángulo similar de relaciones para dar cuenta de los procesos constructivos en el aula. A respecto señala Marchesi, resumiendo a Coll, que"la concepción constructivista nos demuestra que el aprendizaje escolar es el resultado de un proceso complejo de intercambios funcionales que se establecen entre los elementos: el alumno que aprende, el contenido que es el objetivo del aprendizaje y el profesor que ayuda al alumno a construir significados y atribuir sentido a lo que aprende" (p311). El triángulo de Coll, centrado en las personas, tiene la desventaja de consolidar los procesos constructivos enseñanza de aprendizaje por el anclaje que comporta la adscripción de dos de los vértices del triángulo a las personas que se involucran en él. Los procesos, entonces, están constituidos por los catetos del triángulo como elementos que relacionan a los vértices, reproduciéndose la figura metafísica de la que hemos hablado en principio: la comunicación pedagógica solitaria entre un docente y un alumno individuales. Marchesi trasluce esta concepción al profundizar en la idea diciendo que "lo que el alumno aporta al acto de aprender, su actividad mental constructiva, es un elemento mediador entre la enseñanza del profesor y los resultados del aprendizaje a los que llega. De manera recíproca, la influencia educativa que ejerce el profesor a través de la enseñanza, es un elemento mediador entre la actividad mental constructiva del alumno y los significados que vehiculan con los contenidos escolares. La naturaleza y las características de estos contenidos, por último, hacen a su vez de mediadores de la actividad que el profesor y el alumno desarrollan sobre ellos" (op cit). Nos parece que la individualidad de los vértices no deja de traer consecuencias, como la atribución de los procesos de enseñanza a la figura del docente con exclusión de otras posibilidades. Nos ha parecido importante centrar nuestra propia concepción del tema en función de procesos (de enseñanza, aprendizaje conocimiento) con la intencionalidad de buscar un objeto que pueda cubrir mejor las posibilidades de interpretación de los fenómenos a que deseamos acercarnos.

Por último, este objeto tiende a producir un recorte en la mirada evaluativa, en tanto que evaluaremos la función del docente desde la perspectiva de estos procesos de vinculación. Este recorte tiene la virtud de excluir áreas de desempeño que de otra suerte borronean la comprensión del académico en sus diversas funciones de investigador, docente, etc.

\section{DIAGNÓSTICO DE LOS INSTRUMENTOS EMPLEADOS EN LA UNIVERSIDAD}

Tras recopilar los instrumentos utilizados en la Universidad durante el año 2002 agrupamos los reactivos de acuerdo a la fuente de información empleada, los estudiantes, resultando un total de 42 criterios. Una primera división surgió entre criterio pertinentemente focalizado y criterios no focalizados. Los primeros eran aquellos que entraban en el rango de mirada atribuible al estudiante, los segundos excedían ese rango. Dentro de los 
criterios focalizados percibimos cinco sub grupos: criterios administrativos, rasgos personales del docente, coordinación curricular, desarrollo del curso y resultados del curso.

A nuestro juicio, debíamos pronunciarnos respecto de tres inconvenientes básicos que presentaban los instrumentos usualmente empleados en la Universidad para evaluar la docencia:

a) Su orientación al control administrativo más que a la valoración.

La mayor convergencia entre los instrumentos se produjo en este subgrupo en torno a cuatro criterios:

- Asistencia y puntualidad del docente

- Entrega y cumplimiento del programa.

- Cumplimiento de plazos.

- Comentario de los resultados de evaluaciones.

Esto refleja, de un lado, una mayor preocupación por aspectos administrativos que propiamente docentes, en el entendido de que estimamos como aspecto central de la docencia la gestión del conocimiento; por otro lado, muestra los problemas de la evaluación del docente pues estos aspectos se ofrecen como elementos más fácilmente evaluables frente a la complejidad propia del punto que nos interesa.

b) El descentramiento de la mirada evaluativa respecto del objeto a evaluar.

Utilizando sólo al estudiante como fuente de información y frente a la complejidad del fenómeno docente de las que es preciso dar cuenta, no es de extrañar que se sobreexplote el rango de mirada que ellos pueden ofrecer. Esto tiene dos cauces:

- Confusión de la evaluación docencia-docente

- Carencia de fuentes de información para el proceso de evaluación.

La confusión mencionada no es otra que la ausencia de un objeto preciso y explícito al cual evaluar. La presencia de criterios como la "disponibilidad de materiales y fuentes de información" no se explican como elementos de juicio respecto del docente sino de la docencia, en particular de los factores logístico institucionales que modelan el desempeño, quedando fuera del alcance de responsabilidad profesional del docente. Se mezclan así elementos relativos al docente y a la docencia, entendida ésta como el conjunto de factores modeladores del desempeño del docente, sean infraestructurales, curriculares, o logísticos.

En relación a la carencia de fuentes informativas, el estudiante viene a ser el único recurso para dar cuenta de multiplicidad de factores, pero en el afán de obtener información se deja de cautelar la pertinencia entre infor- 
mación e informante. Ello es visible, por ejemplo, en el empleo de criterios como el "nivel de preparación de las clases del docente", la "calidad y actualidad de las fuentes de información", la "habilidad metodológica del docente" o su "dominio disciplinario", más aún cuando este último criterio, el de mayor convergencia en este subgrupo, se evalúa a partir de la "seguridad" con que se expresa el docente frente a los estudiantes, es decir, un factor puramente seductivo para un criterio que debiera apuntar a lo argumentativoracional.

Nuestra objeción en ambos casos no es en relación a estos elementos disruptores por sí mismos, sino en cuanto desperfilan el objeto que se pretende informar y sobrepasan la perspectiva óptica del informante empleado, todo lo cual hace necesario repensar tanto el instrumento como las fuentes.

c) La existencia de un modelo no declarado de docencia como norma evaluativa.

Tácitamente los instrumentos empleados en la Universidad validan un perfil docente particular, a través de criterios como los relativos a los rasgos personales del docente, dentro de los criterios focalizados:

- Capacidad de exposición y explicación del docente

- Hace énfasis en lo relevante.

- Presenta enfoques críticos.

Todos ellos nos dan señales de la presencia implícita de un docente considerado como único agente en el proceso de formación. Es él quien responde, quien hace énfasis, quien explica, quien presenta enfoques, pero nada se dice de su capacidad para plantear problemas, gestionar la duda, 0 gatillar enfoques críticos de parte de los estudiantes. El criterio "estimula la participación de los estudiantes en clases" viene a refrendar esto en el sentido de que si la exposición, validada implícitamente, excluye, de suyo, al oyente, es natural que exista un criterio complementario que valore el esfuerzo del docente por estimular la participación, ya que ella resulta un anexo a lo que es el centro de la práctica docente así entendida: la actividad del propio docente, su discurso. A estos rasgos, que nos dan cuenta de una práctica docente heterónoma y centrada en el docente como elaborador del conocimiento, se agregan otros como la "receptividad y empatía con los estudiantes dentro y fuera del aula", la "capacidad de motivación" o la "amenidad en la exposición" que nos muestran de qué modo se sustenta este perfil implícito en un modelo de corte vocacional que se afirma en el supuesto de que las competencias docentes dependen de rasgos de personalidad más que de un hacer profesional constituido por la reflexión y el conocimiento. Es lo que Gimeno ha llamado la profesionalidad como "una 
pulsión personal relacionada con características de la personalidad inherentes al candidato a docente, con la vocación" (1997; p144).

Es necesario reiterar que todo esto no nos parece negativo per se, sino que no nos parece que éste u otro perfil docente sean los únicos validables, y menos aún que esa validación permanezca implícita, en contra del carácter situado que debe tener la reflexión pedagógica.

\section{OBJETO, DIMENSIONES Y CRITERIOS}

Del diagnóstico quedaba clara la presencia de un modelo lineal, heterónomo y vocacional de la docencia universitaria. Según este modelo, la docencia es un proceso secuencial de tareas que van desde la planificación a la evaluación de los estudiantes, tareas que se llevan a cabo de mejor 0 menor modo dependiendo de los rasgos de personalidad. Percibimos entonces que faltaba un enfoque problematizador de la docencia que permitiera recabar información más sustantiva del quehacer docente, más allá de llegar a saber, por ejemplo, si el docente entrega o no a tiempo el programa, para avanzar en una comprensión de qué hace al dar a conocer ese programa. La planificación, la evaluación del aprendizaje, etc., se nos presentaban como meras tareas o actividades que el docente realiza durante el transcurso del período lectivo, pero poco decían del fenómeno docente mismo del que forman parte. La secuencialidad de esta concepción nos escamoteaba las aristas más sustantivas de lo que a nosotros nos preocupaba: la gestión del conocimiento. Es así como quisimos avanzar en la revisión del concepto de docencia desde el interés en la profesionalización de la docencia, docencia entendida como la práctica de un colectivo que comparte ideas, creencias, valores, disciplina, es decir, que coexisten en el mismo habitus docente. La enseñanza, en palabras de Schulman, (2001) "se inicia con un acto de razón, continúa con un proceso de razonamiento, culmina con la acción de impartir, sonsacar, hacer participar, o seducir, y luego es objeto de mayores reflexiones hasta que el proceso puede reiniciarse", es decir, se concibe "como un acto de comprensión y razonamiento, de transformación y reflexión" (p182). De no situarnos en torno a la profesionalización docente a partir de la premisa reflexiva, corremos el riesgo de caer en la situación descrita por Burbules y Densmore: citado en Imen P., "las propuestas que hacen hincapié en la profesionalización de la enseñanza no son más que el reverso de los informes que culpan a los profesores en prime lugar" (http://www.ctera.org.ar), en cuanto profesionalización presupone el concepto de no - profesional, con exclusión e todas aquellas prebendas sugeridas por el status connotacional del término. Aludir a la profesionalización docente es referirse a su estatuto no - profesional, a su condición de oficio. Pero el concepto de profesión, desde esta óptica, es el de la profesionalidad definida por la racionalidad técnica. Ella es una epistemología de la práctica que se deriva de la filosofía positivista y se construye 
sobre los propios principios de la investigación universitaria contemporánea (Shils, 1978). La racionalidad técnica defiende la idea de que los profesionales de la práctica solucionan problemas instrumentales mediante la selección de los medios técnicos más idóneos para determinados propósitos. Los profesionales de la práctica que son rigurosos resuelven problemas instrumentales bien estructurados mediante la aplicación de la teońa y la técnica que se deriven del conocimiento sistemático, preferiblemente científico". (Schön, 1992; p17).

Pablo Imen acierta al proponer que la profesionalización docente debe estar cruzada por dos ejes en torno a tres componentes ineludibles, más allá de la caracterización taxonómica de la profesionalidad (autonomía profesional, trabajo libre de supervisión; motivación de servicio público; acervo de saber experto, control de la formación o certificaciones de los nuevos profesionales; autogobierno, autoridad propia en la política de su campo) derivada de una suerte de mitología acerca de las llamadas profesiones liberales. Los ejes son los de reinterpretación y reconstrucción. El primero alude a la posibilidad de comprender la docencia desde nuevos marcos y referentes, mientras que la reconstrucción es "una modificación estructural que hace posible renovar aquello que está enmohecido" (Imen, http:// www.ctraorg.ar. Estos dos ejes transversales cruzan tres componentes básicos de la profesionalidad docente en una comprensión reflexiva:

- La necesaria reflexión individual sobre la práctica.

- El intercambio de experiencias y reflexiones en un espacio colectivo.

- La gestión y comunicación y conservación de la reflexión para constituir un campo intelectual dinámico.

Esta posibilidad se fundamenta en la "creación de espacios donde la reflexión individual y colectiva plantee la posibilidad de preguntarse sobre las razones de la propia tarea, que permita argumentar los fundamentos de las propias decisiones y tomar parte en la definición de los medios y los fines de las relaciones pedagógicas" (Imen, http://www.ctera.org.ar).

La necesidad de la permanente revisión de la propia práctica es consustancial a la práctica docente, si asumimos la visión de la profesionalidad del docente en tanto "profesional inevitablemente activo". "Todo ser humano construye significados intelectuales sobre las realidades en las que opera, codifica su experiencia y la racionaliza de algún modo, elaborando explicaciones de la misma" (Gimeno, 1997; p146).

Entenderemos esta mirada autorreflexiva al proceso docente que se hace desde los componentes mismos de ese proceso (ideas, creencias, valores, propósitos, etc.) en tanto herramientas y, a la vez, instrumentos de análisis, desde el concepto de recursividad. "Recursividad no sólo es la simple repetición, sino la crítica de las condiciones de posibilidad de los fundamentos, 
o también la reutilización (i.e. relectura de) los mismos axiomas para resolver nuevas cuestiones, nuevos problemas. Implica potencialmente siempre una explicitación de los axiomas indecidibles del sistema formal implícito" (Mancuso, 1999). La reflexividad, entonces, viene a ser constitutiva de la labor de los prácticos docentes, y no una marca particular de ciertos modelos teóricos de la profesionalidad. La diferencia se establece más bien en la forma de articular los referentes, los procesos de inclusión y exclusión de factores en el proceso reflexivo, desde la tendencia al solipsismo en la perspectiva de contenidos a la mirada ecológica y dialógica en la perspectiva de procesos No contemplar esta consustancialidad del hacer docente y de la reflexión es caer en la conceptualización del docente como un ente meramente operativo, sin capacidad de control ni gestión de la heterogeneidad de variables que cotidianamente asaltan su práctica.

Desde esta dimensión sustantiva de la profesionalidad docente vemos convocadas al menos a otras tres dimensiones que involucran las reflexiones del docente:

- sobre sus propios supuestos, creencias, es decir, sobre su soporte conceptual, pedagógico y disciplinario;

- sobre la trama de relaciones establecidas en el desarrollo del proceso formativo con sus estudiantes, en términos de sus procesos de aprendizaje, sus capitales culturales y los procesos de negociación de conocimiento; y

- sobre la satisfacción de las demandas y requerimientos que le plantean diversas instancias que tensionan su práctica.

A estas dimensiones las hemos denominado dimensión de propuesta docente, de interacción pedagógica educador-educando y de satisfacción de necesidades, respectivamente.

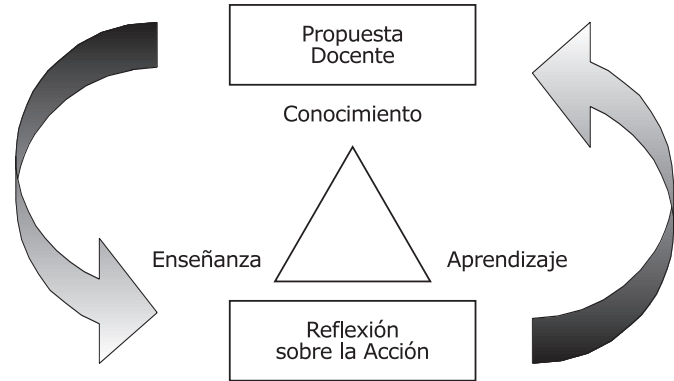

Cada una de estas dimensiones muestra aspectos diversos de la relación entre los procesos de enseñanza, aprendizaje y conocimiento. Si bien la reflexión sobre la acción las cruza a todas permanentemente y se halla implícita en los criterios de cada una, nos parecía importante pesquisar al menos dos elementos de ella que resultan relevantes en la etapa que nos encontramos trabajando: la validez otorgada a los interlocutores en el pro- 
ceso docente, y la recursividad entendida como la articulación de factores para el proceso de reflexión, tal y como ya la hemos descrito.

Estos dos elementos son los criterios que por ahora constituyen esta dimensión en lo que a evaluación del docente por los estudiantes y autoevaluación del docente se refiere. En cuanto a la dimensión de propuesta docente, los criterios que la componen son los principios evaluativos que sustenta el docente en su discurso y que perciben los estudiantes en su práctica, junto con las formas de selección y organización del conocimiento. La dimensión de interacción la integran tres criterios: la relación teoníapráctica propiciada por el docente, las formas de acceso al conocimiento con que media la vinculación entre procesos de aprendizaje y de conocimiento, y las características que adopta, en lo que al conocimiento se refiere, la relación interpersonal que en el aula organiza las interacciones docente-estudiantes y estudiantes-estudiantes. Finalmente, dos elementos nos interesaban de la dimensión de satisfacción de necesidades: la formación valórica promovida y el concepto formativo que plasman los docentes, permitiéndonos esto apreciar en el nivel micro cómo se cristalizan las aspiraciones y demandas macro impuestas institucionalmente por el modelo de hombre que se quiere formar, referenciado en el perfil de egreso de la carrera.

"Los estándares de desarrollo están diseñados para fomentar el desarrollo de los conocimientos y capacidades de los profesores especificando las áreas de capacidades u objetivos de mejora" señala Bacharach y agrega que "dicho modelo se basa en el principio de que todos los profesores deben mejorar no porque sean incapaces de cumplir con sus responsabilidades, sino porque siempre hay espacio para más conocimientos y porque el crecimiento, en sí, es una necesidad básica de los que ocupan puestos profesionales" (citado en Millman y Hammond, 1997, p193). Para nosotros este crecimiento es secundariamente individual y primariamente institucional. Ello desde la óptica que el concepto de valor que hemos asumido como oriente de la mirada evaluativa nos propicia. Crecimiento o desarrollo, en lo referido al docente individual, es el acercamiento al perfil docente que su unidad académica ha definido como óptimo; en tanto que a nivel institucional, esto es, de la unidad académica, es el proceso de desarrollo de ese perfil, madurando su explicitación y solucionando sus contradicciones internas.

En nuestro modelo, los criterios permiten un crecimiento profesional fortaleciendo la vinculación docente-unidad académica, a la vez que la relación unidad académica-institución. El primer proceso resulta del contraste entre las miradas del alumno, del propio docente, de los pares y superiores respecto del desempeño del docente evaluado, a la luz de la norma evaluativa de la unidad; evidenciando la distancia percibida entre norma y desempeño a partir de la información entregada por estos actores. El segundo proceso es resultante del establecimiento de un lenguaje común para la evaluación, lenguaje que permite respetar y valorar la diversidad de las unidades desde 
la mirada global de la Corporación. Esto ocurre así porque cada criterio se compone, realidad, de tres sub-criterios que dan cuenta de la manera en que se manifiesta un aspecto de la variable desde cada uno de los énfasis distinguidos: en contenidos, objetivos y procesos. La norma evaluativa resultante, entonces, es igual a la jerarquización de cada perspectiva en los nueve criterios de la propuesta, de lo cual se derivan normas según se organicen las preferencias de acuerdo a criterios consensuados en las unidades académicas. Lo que tradicionalmente ha ocurrido es la existencia de criterios únicos con valoraciones únicas que no se flexibilizan contextalmente, lo que causa los problemas de consenso de modelo docente implícito. Veamos lo que ocurre en nuestro modelo con el criterio "acceso al conocimiento", de la Dimensión de Interacción:

\section{El docente promueve el aprendizaje}

- por reproducción discursiva de la estructura codificada y manejo de sus reglas de producción.

- por ejercitación y aplicación de procedimientos técnicos codificados

- por interpretación, apropiación y cuestionamiento de ideas y procedimientos.

Cada descripción o subcriterio intenta mostrar su especificidad sin una valoración previa que tamice negativamente, por ejemplo, la reproducción discursiva mediante la cual opera evaluativamente el énfasis en contenidos. De hecho, debe reconocerse que tiene aspectos positivos, como lo es el de ser altamente económica. En su vertiente comprensiva, en palabras de Romeo, ella permite el acceso del aprendiz a la vida investigativa de la comunidad, en una relación docente-estudiante centrada en el trabajo de este último en términos del manejo de las reglas, explícitas o implícitas, de creación del conocimiento y que van desde la valoración de ciertas formas peculiares de la escritura al dominio y adscripción a ciertos sectores del canon disciplinario.

Y si bien puede parecernos indefendible un acercamiento al conocimiento como éste, seguramente estaremos de acuerdo en un grado algo mayor en que hay elementos estandarizados de cualquier profesión que deben ser asimilados por el aprendiz de manera asimismo estándar pues ello es prueba de calidad. Este es el caso, por ejemplo, que nos ha tocado ver más nítidamente en el área de la salud. Desglosar procedimientos en tareas menores, exponer al aprendiz a contextos controlados de práctica y ejercitación, etc., se perciben como procesos válidos y deseables de producir un aprendizaje con umbrales de aceptabilidad claramente especificados. La creatividad, en este punto, resulta tan amenazante del producto final, que su mención en cualquiera de sus modos resulta simplemente impropia. Se debe proteger con la máxima cautela posible la eficiencia en pro de la responsabilidad que el futuro profesional tendrá respecto del sagrado bien de la vida humana. 
Preciso es, en suma, adentrarse en el habitus docente de cada unidad para poder entender lo positivo o lo negativo de un énfasis o del otro. Preciso es, además, ser respetuoso de ese habitus, de sus valoraciones, sus creencias, sus antagonismos internos, sus ideales. Si se pretende propiciar significativamente, en el sentido técnico del término, una reflexión sobre la práctica auténtica, no es posible iniciarla validando estándares 0 criterios evaluativos ajenos al soporte experiencial y conceptual del habitus en que esa práctica existe. Cada unidad académica, por ende, determina su norma, pero también determina una jerarquización de los tres énfasis en cada criterio. Esto permite que, habiendo un tipo de desempeños de carácter ideal, puedan existir desempeños menos correctos, pero no lisa y llanamente incorrectos, como segunda prioridad. Las preguntas se componen, entonces, de cuatro opciones, tres de las cuales corresponden a descripciones, según la situación 0 tema de la pregunta, moduladas de acuerdo a los tres énfasis. La norma así constituida es igual a la jerarquización de las tres perspectivas en los nueve criterios, la cual se contrasta con las respuestas de los estudiantes a las diez y ocho preguntas de la Encuesta de Evaluación. Hasta hoy, ambos instrumentos coinciden en preguntas y criterios, pues de los cuatro instrumentos que componen la propuesta total hemos desarrollado estos dos. Lo lógico es que la Encuesta de Autoevaluación continúe creciendo para albergar la mirada del docente respecto de la mirada de los superiores y de sus pares académicos, próximos instrumentos a ser elaborados. La Autoevaluación se encuentra en el centro pues el discurso del propio docente sobre su práctica resulta primordial para su desarrollo.

Quien evalúa al docente es, en suma, no los estudiantes ni ninguna de las fuentes de información empleadas por sí solas, sino la unidad académica. Sólo en el contexto de cotejo con la norma que ha establecido puede valorarse la información provista por éstas, pues los instrumentos carecen de valoraciones explícitas en su construcción, lo cual permite que los informantes sean efectivamente eso: quienes procuran el necesario conjunto de datos para la evaluación, pero no quienes se pronuncian sobre lo positivo y negativo, en tanto que esa función la hemos dejado en las manos de la unidad académica como comunidad docente.

Se espera, así, contribuir al desarrollo de una cultura evaluativa explícita, colectiva, sinérgica y participativa en que se cohesione lo local y lo institucional de la Corporación, dando una perspectiva integradora al desempeño de cada docente individual a la luz de los propósitos, metas y anhelos docentes que hacen realidad la misión formadora de la Universidad de Chile. 


\section{REFERENCIAS BIBLIOGRÁFICAS}

Angulo, F. 1996

Bacharah, 1997

Bourdieu, P. 1990

Bourdieu, P. 1997

de Miguel, M. 1991

Gimeno, J. 1997

Imen, $\mathbf{P}$.

Mancuso, H. 1999

Marchesi A. y H. Martin, 2000

Millman J. y L. Darling-Hammond, 1997

Romeo, J., 1998

Ruiz, J., 1999

Schön, D. 1992

Schulman, L. 2001

Tamayo A. 1999
La evaluación del profesorado universitario. En: Reforma y Evaluación de la Universidad. Universitat de Valencia, Valencia. pp165-188

Como evaluar al profesorado para promociones y aumentos salariales. En: Milman y Hammond, Manual para la Evaluación del Profesorado. Editorial La Muralla, Madrid, pp188-207

Lo que quiere decir hablar, En: Sociología y Cultura. Grijalbo, México; 317pp.

Espacio social y espacio simbólico. En: Razones prảcticas: Sobre la teoría de la acción. Anagrama, Barcelona; 237pp.

Criterios para la evaluación del profesorado universitario. Universidad de Oviedo, España; 170pp.

Docencia y cultura escolar. En: Ideas, Buenos Aires; 172pp.

En torno a la profesionalización docente y las instituciones educativas: apuntes para el debate, en http://www.ctera.org.ar

Patrones, recursividad y autorreferencia de pi en Pi: el problema de la recursividad y la autorreferencia de los sistemas semióticos/pensantes. En: ponencia presentada a las Primeras Jornadas Interdisciplinarias sobre ética, estética y psicoanálisis, Universidad de Buenos Aires, Centro Cultural San Martín de Buenos Aires, en http://www.otrocampo.com/2/314.html

Calidad de la enseñanza en tiempos de cambio, Alianza, Madrid, 498pp.

Consecuencias deseadas e imprevistas, propósitos y efectos de la evaluación del profesorado. En: Millman Jasón y Darling-Hammond, Linda (Eds.) Manual para la evaluación del profesorado. Editorial La Muralla, Madrid.

Perspectivas del currículo en educación superior. En: Revista Enfoques Educacionales, Santiago, 1 (1): pp5772.

Cómo hacer una evaluación de centros educativos. Edit. Narcea, Madrid; 350pp.

La formación de profesionales reflexivos. Paidós, Barcelona; 310pp.

Conocimiento y enseñanza. En: Revista de Estudios Públicos (83) Centro de Estudios Públicos, Santiago, pp163-196.

Cómo identificar formas de enseñanza. Magisterio, Colombia; 115pp. 
Villa A. (Ed.) 1993

Vygotski, L. S. 1988
La evaluación del profesor: una visión de los principales problemas y enfoques en diversos contextos. Servicio Central de Publicaciones del Gobierno Vasco, España; 364pp.

El desarrollo de los procesos sicológicos superiores. Crítica, Barcelona; 226pp. 